\title{
Prevalence, morbidity and treatment seeking behavior for allergic conjunctivitis in children in a North Indian community ${ }^{\text {it }}$
}

\author{
Payal Kahol $^{\mathrm{a}, *}$, Manjula Thakur ${ }^{\mathrm{a}}$, Amit Gupta ${ }^{\mathrm{b}}$, Sushma Kumari Saini ${ }^{\mathrm{a}}$

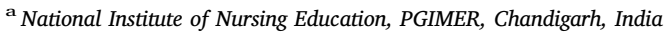 \\ ${ }^{\mathrm{b}}$ Department of Ophthalmology, PGIMER, Chandigarh, India
}

\section{A R T I C L E I N F O}

\section{Keywords:}

Allergic conjunctivitis

Prevalence

Morbidity

Treatment seeking behavior

India

\begin{abstract}
A B S T R A C T
Purpose: To assess the prevalence, morbidity and treatment seeking behavior amongst children aged 5-15 years, suffering from allergic conjunctivitis.

Methods: A cross-sectional survey was done in a semiurban low-income community in Chandigarh, India. Children of age group 5-15 years, having allergic conjunctivitis were identified by systematic random sampling technique. A survey proforma and an interview schedule was used to gather information on socio demographic profile and data pertaining to allergic conjunctivitis and related morbidities among the study subjects. Intensity of symptoms of allergic conjunctivitis was also assessed using proforma and an observation checklist. Results: A total of 217 subjects were enrolled. Prevalence of allergic conjunctivitis was $12.22 \%$. Occurrence was more in males (13.44\%) than females $(10.71 \%)$. Itching and frequent eye rubbing were the commonly reported symptoms. Dust (35\%) was the most common precipitating factor and perennial conjunctivitis was more common (54.8\%). Reported co-morbidities included allergic rhinitis / hay fever (23.9\%), dermatitis (9.7\%) and asthma (0.5\%). Only 44\% subjects had sought treatment from a doctor; and barely $11 \%$ completed their treatment.

Conclusions: Allergic conjunctivitis has a high prevalence among children but is frequently overlooked. Inspite of its frequency, treatment seeking behavior is low amongst the affected population. Identification of patients and their appropriate treatment is important to improve the ophthalmic health of the community.
\end{abstract}

\section{Introduction}

Allergy is a medical problem which affects more than $15 \%$ of the world population. ${ }^{9}$ Allergic tendency tends to target more than one organ system in the body and hence, the patient may have symptoms related to multiple organ systems. ${ }^{6,12}$ However, ocular component is frequently the most prominent and disabling feature of their allergy as it leads to continuous symptoms like itching and watering of eyes, which leads to significant irritation. ${ }^{3}$ The prevalence of allergic conjunctivitis is surprisingly high and it is supposed to be the most common allergic disorder. Currently it is estimated that at least $20 \%$ of the general population suffers from some form of allergic conjunctivitis. ${ }^{5}$

Numerous reports indicate that the incidence and prevalence of allergic conditions have increased dramatically all over the world during the past 40 years and they continue to rise. ${ }^{4,11}$ This is because of rapid urbanization, industrialization, increased air pollution and dry- eye syndrome. ${ }^{10}$

Allergic conjunctivitis is often under-diagnosed and consequently undertreated. Recurrent symptoms for several years may turn patient behavior towards under-reporting of problems and ignoring ocular care. Patients of allergic conjunctivitis, having significant debilitating symptoms like itching, watering of eyes and ropy discharge have interference in their day to day activities, difficulty in concentrating in their work and these adversely affect their quality of life. ${ }^{7}$ These aspects underscore the importance of estimating the disease burden and its consequent morbidity in the community. Hence the present study was undertaken to assess the prevalence, morbidity features and treatment seeking behavior amongst children of 5-15 years age group.

\section{Material and methods}

The study was conducted in a low income community of North

\footnotetext{
The authors declare that this submission has not been published anywhere previously / presented anywhere and that it is not simultaneously being considered for any other publication.

* Corresponding author. National Institute of Nursing Education, PGIMER, Chandigarh, India.

E-mail address: palukahol@rediffmail.com (P. Kahol).
} 
Chandigarh, India having 3003 numbered houses with a population of 18,000 approximately as per the official records. The residents of the colony are migrants from different states of India like Punjab, Haryana, Bihar, Rajasthan, Uttar Pradesh and neighbouring countries like Nepal. Majority of people residing here belong to a low socio economic group and are unaware of the diseases so they tend to ignore many health problems until their condition becomes severe. All the houses of the colony were divided into six strata of 500 houses each. Randomization of these strata was done to experimental and control by lottery method in which three groups of 500 houses each were in experimental group and three in control group. Sampling technique employed was systematic random sampling. Every 2nd house was surveyed (even numbered house, selected by lottery method) to identify the subjects of 5-15 years having allergic conjunctivitis. The tool was developed by relevant literature search on allergic conjunctivitis through books, national \& international journals and internet search and validated by experts in the field of nursing and department of ophthalmology. The tools developed in the study included a survey proforma to identify the children suffering from allergic conjunctivitis; an interview schedule to gather information on socio demographic profile and data pertaining to allergic conjunctivitis in the study subjects. Assessment proforma and observation checklist were used to collect data on the intensity of the symptoms of in allergic conjunctivitis. A house to house survey was conducted to identify the study subjects. The children of age group 5-15 years and their care givers were interviewed as per survey proforma and children with the symptoms of allergic conjunctivitis were enrolled in the study. Any child, male or female in the age group of 5-15 years; presenting with any three of the following symptoms itching, ropy discharge, frequent eye rubbing, redness or watering of eyes for minimum of one week was diagnosed as having Allergic Conjunctivitis.

The sample size was calculated by using "Statcalc Software" (Epi Info) taking prevalence of $15 \%$, error interval of $5 \%$ at the confidence interval of $95 \%$ and $5 \%$ level of significance which came out to be 187 and by adding $10 \%$ of dropouts $(187 \times 10 / 100=18.7-19)$, so the sample required is $187+19=206-210$. Total 1775 children were contacted out of which 217 were identified with the symptoms of allergic conjunctivitis. Subjects older than 10 years were interviewed as per interview schedule and the data was supplemented by their mothers, while in case of younger children of age less than 10 years, their mothers were interviewed.

Score for each symptom was categorized on a scale of (0-10). They were categorised as - no symptom - (0 score), mild- (0.1-3 score), moderate- (3.1-7 score) and severe- (7.1-10). The individual scores of all the symptoms were added and divided by 5 to obtain the average scores (0-10); i.e. overall intensity of symptoms of allergic conjunctivitis. This overall intensity of symptoms was further categorized as mild- (0.1-3 score), moderate- (3.1-7 score), severe- (7.1-10 score). The data was analysed using standard SPSS-16 software.

\section{Results}

Table 1 depicts the Socio demographic profile of the respondents. Mean age of the subjects was $9.59 \pm 3.07$ years with a range of 5-15 years. Male respondents were more than female. As per the educational level $38.2 \%$ of the subjects had upto primary level of education. Majority (94\%) of the subjects were Hindus and $53.9 \%$ of the subjects were living in nuclear family. As per family size, $51.6 \%$ of the subjects had 58 members in their family and the range for the number of family members living together was 3-16.

Considering environmental factors, liquefied petroleum gas was the type of fuel used by majority (95\%) of the families and most of the
Table 1

Socio-demographic profile of the respondents $\mathrm{N}=217$.

\begin{tabular}{ll}
\hline Socio-demographic character & $\mathrm{n}(\%)$ \\
\hline Age (yrs) & \\
$5-8$ & \\
$9-11$ & $83(38.2)$ \\
$12-15$ & $69(31.8)$ \\
Sex & $65(30.0)$ \\
Male & \\
Female & $132(60.8)$ \\
Education of the child ${ }^{\mathrm{b}}$ & $85(39.2)$ \\
upto Primary school (upto 5th std) & \\
upto Middle school (5th - 8th) & $83(38.2)$ \\
upto High school (9th - 10th) & $69(31.8)$ \\
Religion & $65(30.0)$ \\
Hindu & \\
Muslim & $204(94.0)$ \\
Sikh & $2(0.9)$ \\
Christian & $8(3.7)$ \\
Type of family & $3(1.4)$ \\
Nuclear family & $117(53.9)$ \\
Joint family & $100(46.1)$ \\
Family size (Total living house members) & \\
$\quad<4$ & $69(31.8)$ \\
5-8 & $112(51.6)$ \\
9-12 & $30(13.8)$ \\
13-16 & $6(2.8)$ \\
Type of fuel used & \\
LPG & $206(94.9)$ \\
Kerosene oil/cow dung/coal/wood & $11(5.1)$ \\
Separate Kitchen in the house & $179(82.4)$ \\
Pet kept in the house & $22(10.1)$ \\
\hline
\end{tabular}

\footnotetext{
${ }^{\text {a }}$ Mean \pm S. D (Range) in yrs: $9.59 \pm 3.07$ (1-11).

b Range: $1-11$ class.

${ }^{c}$ Range: 3-16.
}

houses $(82.4 \%)$ had separate kitchen in their house. Very few $(10.1 \%)$ had kept a pet in their house.

\subsection{Prevalence of allergic conjunctivitis}

From the total 1775 children surveyed, allergic conjunctivitis was found to be prevalent in 217 (12.22\%) subjects. Prevalence was higher amongst males $(13.44 \%)$ than in females $(10.71 \%)$.

\subsection{Episodes of allergic conjunctivitis during the last three months}

Children had single to multiple episodes of the symptoms of allergic conjunctivitis during the last three months of the period of enquiry and very frequent recurrence was reported. During the previous three months, $40.5 \%$ of the subjects had reported 3 episodes of allergic conjunctivitis, $35.9 \%$ had 2 episodes and $15.2 \%$ had 4 episodes. A few subjects (4.6\%) had as many as 5 episodes while $3.7 \%$ had only a single episode of allergic conjunctivitis.

\subsection{Precipitating factors and seasonal variation in allergic conjunctivitis}

Dust, smoke, sunlight pollen/grass/weed, dandruff, dry eyes and cream (cosmetic) were the reported precipitating factors for allergic conjunctivitis (Fig. 1). One third (35\%) of the subjects had reported dust as the most common precipitating factor followed by smoke (19.3\%) and sunlight (14.8\%). Other allergens included pollen, grass and ragweed $(11.9 \%)$, dandruff $(3.2 \%)$, dry eye syndrome $(1.8 \%)$ and cosmetics (1.9\%). 


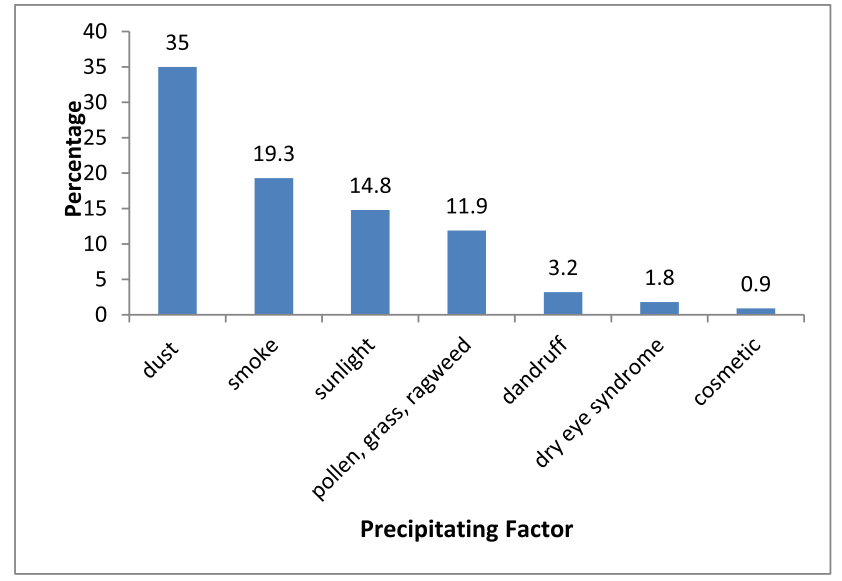

*More than one precipitating factor was reported by the subject

Fig. 1. Prevalence of precipitating factors* of Allergic Conjunctivitis among study subjects. N-217*More

than one precipitating factor was reported by the subject.

More than half (54.8\%) of the subjects reported having symptoms of allergic conjunctivitis throughout the year i.e. perennial allergic conjunctivitis while others reported seasonal variation in the appearance of symptoms. Nearly $22.6 \%$ of the subjects reported having symptoms of allergic conjunctivitis mostly during rainy season whereas $18.8 \%$ reported severe symptoms during the summer season and $4.6 \%$ in winter.

\subsection{Family history of allergic conjunctivitis and co morbidities reported by study subjects}

Most of the subjects $(81.1 \%)$ had no family history of allergic conjunctivitis. In the rest, $14.7 \%$ of the parents/grandparents and $4.1 \%$ of the siblings had history of allergic conjunctivitis.

It was further observed (Fig. 2) that $23.9 \%$ of the subjects had allergic rhinitis/hay fever and few (9.7\%) had associated dermatitis present along with allergic conjunctivitis; while asthma was present in only one subject $(0.5 \%)$. Almost $2 / 3$ rd of the subjects (65.8\%) had no associated co morbidity along with allergic conjunctivitis while.

\subsection{Symptoms of allergic conjunctivitis present in the study subjects}

It was observed that $70.5 \%$ of the subjects had reported 3 symptoms, $23 \%$ had reported 4 symptoms while only $6.5 \%$ of the subjects had reported all the five symptoms in allergic conjunctivitis i.e. itching, frequent eye rubbing, watering of eyes, redness and ropy discharge.

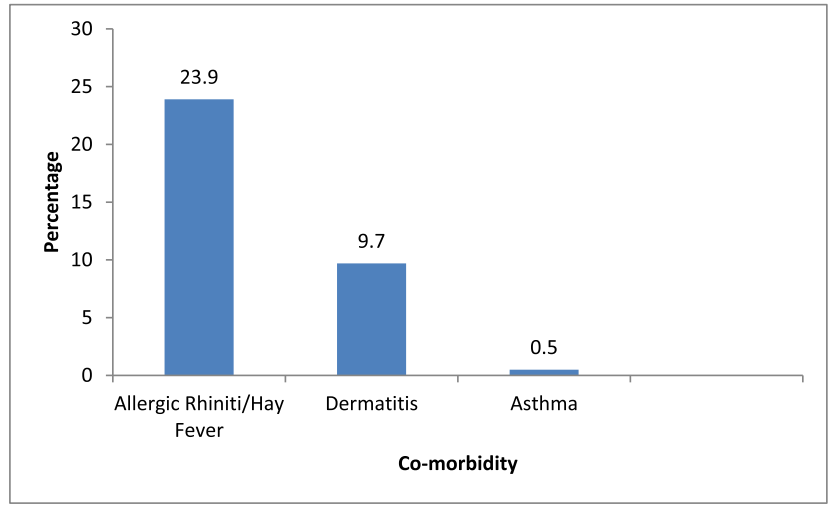

Fig. 2. Co morbidities reported by study subjects N- 217.

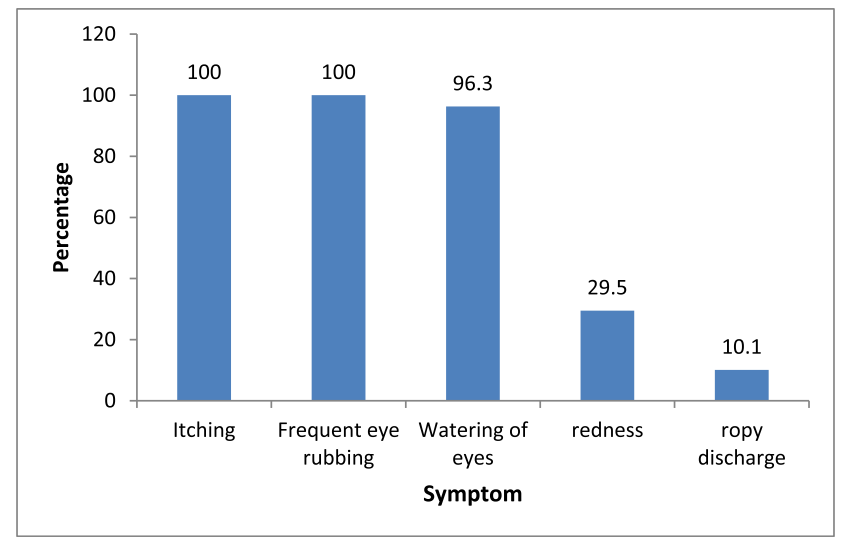

Fig. 3. Symptoms of Allergic Conjunctivitis present in the study subjects N-217.

Table 2

Intensity of symptoms of Allergic conjunctivitis N-217.

\begin{tabular}{lllll}
\hline Symptom & \multicolumn{2}{l}{ Intensity of symptom } & & \\
\cline { 2 - 5 } & $\begin{array}{l}\text { Symptom not } \\
\text { present }\end{array}$ & Mild & Moderate & Severe \\
& $0(0)$ & $2(0.9)$ & $175(80.6)$ & $40(18.4)$ \\
Itching & $0(0)$ & $2(0.9)$ & $175(80.6)$ & $40(18.4)$ \\
Frequent eye rubbing & $8(3.6)$ & $10(4.6)$ & $175(80.6)$ & $24(11.1)$ \\
Watering of eyes & $153(70.5)$ & $13(5.9)$ & $41(18.9)$ & $10(4.6)$ \\
Redness & $195(89.8)$ & $2(0.9)$ & $17(7.8)$ & $3(1.3)$ \\
Ropy discharge & - & $66(30.4)$ & $147(67.7)$ & $4(1.8)$ \\
Overall intensity of all the & - & & & \\
\hline symptoms & & & & \\
\hline
\end{tabular}

${ }^{\text {a }}$ Average scores of all the symptoms.

Itching and frequent eye rubbing were observed in all the subjects; followed by watering of eyes $(96.3 \%)$; while redness was observed in $29.5 \%$ and ropy discharge in $10.1 \%$ of the subject (Fig. 3).

\subsection{Intensity of symptoms of allergic conjunctivitis}

As seen in Table 2, majority of the subjects (81\%) had moderate intensity of itching, frequent eye rubbing and watering of eyes while $18.4 \%$ had severe itching and frequent eye rubbing and $11 \%$ had severe watering of eyes. Moderate intensity redness was present in some subjects (19\%) and ropy discharge in $7.8 \%$ subjects. Severe intensity of redness and ropy discharge was observed in $4.6 \%$ and $1.3 \%$ of the subjects respectively.

Moreover if we see the overall intensity of symptoms of allergic conjunctivitis, most $(68 \%)$ of the subjects had moderate intensity of symptoms while $30.4 \%$ had mild symptoms and only few $(1.8 \%)$ had severe symptoms (Table 2).

\subsection{Treatment seeking behavior of the subjects}

Treatment seeking behavior revealed that about $57 \%$ of the subjects had not consulted any physician for their problem of allergic conjunctivitis. Out of those who consulted a physician, very few $(4.6 \%)$ completed their treatment.

It was also observed that $69.7 \%$ of the subjects with mild intensity of symptoms had not taken any treatment for their symptoms. But as the severity of symptoms increased there was increase in treatment seeking behavior though the treatment was still irregular. It was also observed that $42 \%$ of the subjects with moderate intensity of symptoms 
had taken irregular treatment while $75 \%$ of the subjects with severe intensity of symptoms had taken treatment; that was again, irregular.

Further, only $27 \%$ of the subjects adopted some home based remedial measure for getting relief from symptoms of allergic conjunctivitis $-17.9 \%$ of the subjects washed their eyes with running water and a few (7.3\%) washed their eyes with cold water. One subject had also put gulab jal (rose water extract) in his eyes to get relief from the symptoms of allergic conjunctivitis.

\section{Discussion}

Allergies affect 10 to $20 \%$ of the population. ${ }^{6,9}$ They often run in families. People who have allergies are more likely to develop allergic conjunctivitis as conjunctiva is easily accessible for the allergens to cause allergic reaction and produce symptoms. When the eyes are exposed to allergens like pollen or mold spores, dust, animal dander, perfumes, cosmetics etc. they may become itchy, red and produce watery discharge. The problem of allergic conjunctivitis is associated more with its frequency (episodes) than its severity; as, a single episode may not be very severe but repeated episodes might be debilitating for patients. Although the burden of allergic conjunctivitis is high, ranging from 15 to $20 \%^{1,3,9,12}$; it is frequently overlooked by patients and this condition remains under diagnosed in a majority of the population. ${ }^{5}$

The prevalence of allergic conjunctivitis is reasonably high. In our study, amongst children of age group 5-15 years, prevalence was found to be $12.22 \%$

In the present study it was observed that most of the general population does not know the actual cause of the allergies; thus, it becomes difficult for them to avoid the allergen. Supporting this observation, in the present study, the precipitating cause for allergic conjunctivitis was not known to more than half of the subjects; though rest of the subjects had reported known inciting factors like dust, smoke, sunlight, pollen/grass/ragweed, dandruff, dry eyes and cosmetics. A few subjects reported more than one precipitating factor. Dust and smoke were the common allergens, while pollen, grass or ragweed was reported only in few subjects.

Itching is the most important symptom of this condition, so much so that if itching is absent, the diagnosis of allergic conjunctivitis ought to be questioned. ${ }^{2}$ In the present study, itching and frequent eye rubbing was reported by all the subjects and these symptoms were the basis for the selection of the study subjects.

Ocular allergy in majority of the cases is overlooked and in spite of its interference in day to day activities, people don't seek medical attention. A cross sectional study supported this finding in which only $19.4 \%$ of the subjects had consulted an ophthalmologist and $56.1 \%$ had started with self-treatment. ${ }^{8}$ This was an interesting pointer towards tendency to access medical attention; in the present study it was found that about $57 \%$ of the subjects did not seek any medical treatment from a doctor, however it was noted that with increasing severity of symptoms subjects increasingly sought medical attention.

Health professionals working in community can play a very important role in creating awareness amongst the general public regarding signs and symptoms of allergic conjunctivitis; and they can also identify patients having this affliction. Patients should be made aware of the consequences of neglecting their ocular health; they can also be taught simple cost effective measures like cold compress for getting relief from their symptoms.

\section{Strengths of the study}

$>$ It's a close survey (door to door study) thus enabling picking up of many patients who will otherwise not go to hospital.

$>$ Responding to the questions of this survey proforma enabled patients and their families to increase health awareness about this condition.

\section{Weaknesses of the study}

$>$ As the study relies mainly on subjective responses so $100 \%$ sensitivity and specificity is not ensured.

$>$ Personnel and time limitation did not enable every house to be surveyed.

\section{Conclusion}

The magnitude of allergic conjunctivitis was found $12.22 \%$ which is reasonably high and majority of the subjects had not taken any treatment for getting relief from their symptoms.

\section{Ethical clearance}

Ethical clearance was taken from the Institute ethical committee (PGIMER, Chandigarh). Written informed consent was taken from the study subject. Subjects were empowered with the full autonomy to participate in the research and withdraw at any time. The trial is also registered with Clinical Trials Registry- India (CTRI) with registration number CTRI/2016/02/006586.

\section{Conflict of interest}

The authors declare that none of the authors have any proprietary interests or conflicts of interest related to this submission.

\section{Source of funding}

The authors declare that no financial grant was taken for the study project, the study was self sponsored by the primary author.

\section{Annexure I}

\section{A. Survey Proforma to Identify the Subjects of Allergic Conjunctivitis}

\begin{tabular}{|c|c|c|c|c|c|c|c|c|c|c|c|c|c|}
\hline \multirow[t]{2}{*}{$\begin{array}{l}\text { Identi- } \\
\text { ficationNo }\end{array}$} & \multirow[t]{2}{*}{$\begin{array}{l}\text { S. H.no. } \\
\text { no }\end{array}$} & \multirow{2}{*}{$\begin{array}{l}\text { Name of } \\
\text { the Child } \\
\text { D/o or S/o }\end{array}$} & \multirow[t]{2}{*}{$\begin{array}{l}\text { Age } \\
\text { (yrs) }\end{array}$} & \multirow[t]{2}{*}{$(\mathrm{M} / \mathrm{F})$} & \multicolumn{5}{|c|}{$\begin{array}{l}\text { Symptoms of Allergic conjunctivitis presentmark } \\
\text { ( ), if present and mark }(\mathrm{X}) \text { if not present }\end{array}$} & \multicolumn{2}{|c|}{$\begin{array}{l}\text { If yes, for how } \\
\text { long }\end{array}$} & \multicolumn{2}{|c|}{$\begin{array}{l}\text { Cases of Allergic } \\
\text { conjunctivitis }\end{array}$} \\
\hline & & & & & $\begin{array}{l}\text { Itch- } \\
\text { ng }\end{array}$ & $\begin{array}{l}\text { Freque-nt } \\
\text { eye rubbing }\end{array}$ & $\begin{array}{l}\text { Ropy } \\
\text { discha-rge }\end{array}$ & Redd-ness & $\begin{array}{l}\text { Water-ing } \\
\text { of eyes }\end{array}$ & $<1$ wks & $\geq 1 \mathrm{wks}$ & Yes ( ) & $\begin{array}{l}\text { No } \\
\text { (X) }\end{array}$ \\
\hline
\end{tabular}

Id.no.

Date of interview 
Interview Schedule of Subjects With allergic Conjunctivitis

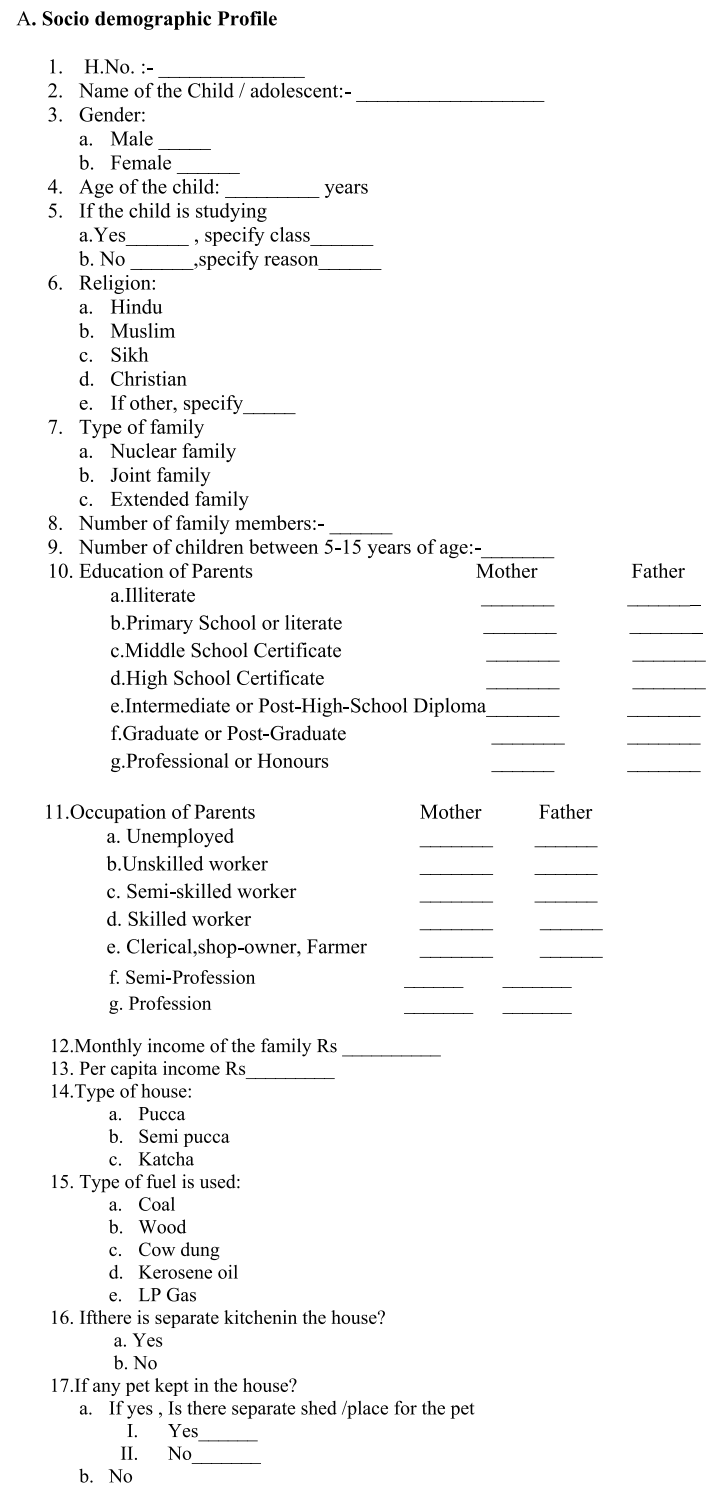

B. Questions related to allergic conjunctivitis

Q. 1 How many times did you experience the symptoms in the last three month? Ans

Q.2 Do you experience these symptoms during particular month/months of the year?

a. Yes, specifymonth

b.No

Q.3 Do you think there is any precipitating factor of the symptoms of allergic conjunctivis?

a.Yes, which

i. Pollen from trees, grass and ragweed

ii. Animal fur and secretions such as saliva

iii. Dust mites

iv. Smoke

v. Cosmetics

vi. Contact lenses and lens solution

vii. Perfumes

viii. Diesel exhaust 


$$
\begin{array}{rr}
\text { ix. } & \text { Medicines } \\
\text { x. } & \text { Eye drops } \\
\text { xi. } & \text { Dry eye syndrome } \\
\text { xii. } & \text { Any other, specify } \\
\text { b. No } \quad &
\end{array}
$$

Q.4 Are you taking any special precautions when the symptoms of allergic conjunctivitis are present?

a. Yes

Q.5 Are you taking any treatment from the doctor for this condition of allergic conjunctivitis?
a. If yes, whether the treatment is
I. Regular
b. No

Q.6 Have you adopted any otherremedialmeasure for getting relief from the symptoms of allergic conjunctivitis?

a. If yes, Specify the treatment

$$
\begin{array}{ll}
\text { I. } & \text { Regular } \\
\text { II. } & \text { Irregular }
\end{array}
$$

b. N

Q.7 If any other member of the familyis suffering from allergic conjunctivitis?

a.If yes, who , have they taken any treatment for it?

b. No

I. Yes

Q. 8 Are you suffering from any of the following conditions?

a. Asthma

b. Dermatiti

c. Allergic Rhinitis

d. Hay fever

\begin{tabular}{|c|c|c|c|c|c|c|c|c|c|c|c|}
\hline $\begin{array}{l}\text { What is the intensity of the following } \\
\text { symptoms }\end{array}$ & Day & $\begin{array}{l}110 \\
\text { paise }\end{array}$ & $\begin{array}{l}220 \\
\text { paise }\end{array}$ & $\begin{array}{l}330 \\
\text { paise }\end{array}$ & $\begin{array}{l}440 \\
\text { paise }\end{array}$ & $\begin{array}{l}550 \\
\text { paise }\end{array}$ & $\begin{array}{l}660 \\
\text { paise }\end{array}$ & $\begin{array}{l}770 \\
\text { paise }\end{array}$ & $\begin{array}{l}880 \\
\text { paise }\end{array}$ & $\begin{array}{l}990 \\
\text { paise }\end{array}$ & $\begin{array}{l}10100 \\
\text { paise }\end{array}$ \\
\hline \multirow[t]{6}{*}{ 1.Itching } & I & & & & & & & & & & \\
\hline & II & & & & & & & & & & \\
\hline & III & & & & & & & & & & \\
\hline & IV & & & & & & & & & & \\
\hline & $\mathrm{V}$ & & & & & & & & & & \\
\hline & VI & & & & & & & & & & \\
\hline \multirow[t]{6}{*}{ 2.Ropy discharge } & I & & & & & & & & & & \\
\hline & II & & & & & & & & & & \\
\hline & III & & & & & & & & & & \\
\hline & IV & & & & & & & & & & \\
\hline & $\mathrm{V}$ & & & & & & & & & & \\
\hline & VI & & & & & & & & & & \\
\hline \multirow[t]{6}{*}{ 3.Frequent eye rubbing } & I & & & & & & & & & & \\
\hline & II & & & & & & & & & & \\
\hline & III & & & & & & & & & & \\
\hline & IV & & & & & & & & & & \\
\hline & $\mathrm{V}$ & & & & & & & & & & \\
\hline & VI & & & & & & & & & & \\
\hline \multirow[t]{6}{*}{ 4.Reddness } & I & & & & & & & & & & \\
\hline & II & & & & & & & & & & \\
\hline & III & & & & & & & & & & \\
\hline & IV & & & & & & & & & & \\
\hline & $\mathrm{V}$ & & & & & & & & & & \\
\hline & VI & & & & & & & & & & \\
\hline
\end{tabular}

e. No

Q. 9 If Kajal is applied on the eyes of the child?

a. Yes

b. No

C. Assessment of intensity of the symptoms related to allergic conjunctivitis 
5.Watering of eyes

\section{References}

1. Baig R, Ali AW, Ali T, Ali A, Shah MN, Sarfaraz A, et al. Prevalence of allergic conjunctivitis in school children of Karachi. J Pakistan Med Assoc. 2010 May;60(5):371-373

2. Bielory L, Meltzer EO, Nicholls KK, Melton R, Thomas RK, Bartlett JD. An algorithm for the management of allergic conjunctivitis. Allergy Asthma Proceedings. [Internet] 2013; 2013:408-420. Available from: www.ncbi.nlm.nih.gov/pubmed/2399823.

3. Biswas J, Saha I, Das D, Bandyopadhyay S, Ray B, Biswas G. Ocular morbidity among children at a tertiary eye care hospital in Kolkata, West Bengal. Indian J Publ Health. 2012;56:293-296

4. Davies RJ, Rusznak C, Devalia JL. Why is allergy increasing?-environmental factors. Clin Exp Allergy. 1998 Dec28;6:8-14.

5. Gomes PJ. Trends in prevalence and treatment of ocular allergy. Curr Opin Allergy Clin Immunol. 2014 Oct;14(5):451-456.

6. Hesselmar B, Aberg B, Eriksson B, Aberg N. Allergic rhinoconjunctivitis, eczema, and sensitization in two areas with differing climates. Pediatr Allergy Immunol.
2001;12:208-215.

7. John LJ, Ahmed S, Anjum F, Kebab M, Mohammed N, Darwich N, et al. Prevalence of allergies among university students: a study from Ajman, United Arab Emirates. ISRN Allergy. 2014 Article ID 502052, 5 pages.

8. Kim HY, Kwon EB, Baek JH, Shin YH, Yum HY,Jee HM, et al. Prevalence and comorbidity of allergic diseases in preschool children. Korean J Pediatr. 2013 Aug;56(8):338-342.

9. Nathan RA, Meltzer EO, Selner JC, Storms W. Prevalence of allergic rhinitis in the United States. J Allergy Clin Immunol. 1997;99:S808-S814.

10. Nimmagadda SR, Evans R. Allergy: etiology and epidemiology. Pediatr Rev. 1999 April;20:11-16.

11. Rachelefsky GS. National guidelines needed to manage rhinitis and prevent complications. Ann Allergy Asthma Immunol. 1999 March;82:296-305.

12. Singla JP, Parashar Y. Prevalence of allergic rhinitis, allergic conjunctivitis and atopic dermatitis in children with recurrent wheeze. Indian Pediatr. 2009;46:262-264. 